\title{
Technology transfer of dynamic IT outsourcing requires security measures in SLAs
}

\author{
Frank Dickmann ${ }^{1}$, Maximilian Brodhun ${ }^{1}$, Jürgen Falkner ${ }^{2}$, Tobias A. Knoch ${ }^{3,4}$, Ulrich \\ $\operatorname{Sax}^{5}$ \\ ${ }^{1}$ Department of Medical Informatics, University of Göttingen, Robert-Koch-Straße 40, \\ 37075 Göttingen, Germany. \\ ${ }^{2}$ Fraunhofer-Institute for Industrial Engineering, Nobelstraße 12, 70569 Stuttgart, Germany. \\ ${ }^{3}$ Biophysical Genomics, Dept. Cell Biology \& Genetics, Erasmus MC, \\ Dr. Molewaterplein 50, 3015 GE Rotterdam, The Netherlands. \\ ${ }^{4}$ Biophysical Genomics, Genome Organization \& Function, BioQuant Center/ \\ German Cancer Research Center, Im Neuenheimer Feld 267, 69120 Heidelberg, Germany. \\ ${ }^{5}$ Department of Information Technology, University Medicine Göttingen, \\ Robert-Koch-Straße 40, 37075 Göttingen, Germany. \\ fdickmann@med.uni-goettingen.de, maxi brodhun@hotmail.com, \\ juergen.falkner@iao.fraunhofer.de, ta.knoch@taknoch.org, usax@med.uni-goettingen.de.
}

\begin{abstract}
For the present efforts in dynamic IT outsourcing environments like Grid or Cloud computing security and trust are ongoing issues. SLAs are a proved remedy to build up trust in outsourcing relations. Therefore, it is necessary to determine whether SLAs can improve trust from the perspective of the outsourcing customer by integration of security measures. The conducted survey indicates that customers see SLAs as an approach to increase their level of trust in IT outsourcing partners. In addition, security measures in SLAs are of high relevance to support trust but not yet integrated appropriately. However, SLAs are very important for the technology transfer of eScience projects in Grid computing. Again, Grid based outsourcing of biomedical IT services requires security measures in SLAs. Thus, the technology transfer process of dynamic IT outsourcing infrastructures requires adequate SLAs in order to be successful.
\end{abstract}

Keywords. Grid computing, technology transfer, distributed IT outsourcing, Service Level Agreements, security, trust.

\section{Introduction}

Present efforts towards Grid and Cloud computing infrastructures are, by their very nature, economically oriented efforts for outsourcing of particular tasks to another economic entity which is specialized in the respective field $[2,3]$. In fact, the ad hoc character of connecting entities is the difference to previous ways of IT outsourcing e.g. hosting. Accordingly, the outsourcing concepts of Grid and Cloud Computing provide more flexibility in multi-institutional IT integration [4]. In Grid and Cloud computing environments the customer is intended to receive IT service power on 
demand [3]. This is to be described in more generic terms as: dynamic IT outsourcing (DITO). Presently, the exact term "dynamic IT outsourcing" is not yet wildly mentioned but definitely hits the heart of the matter [5-7].

A major issue for the service customer in outsourcing IT is trust in the reliability of the service provider [8]. The lack of physical access to outsourced resources is a predominant reason for that trust issue [9]. Besides, trust is a continuous research topic in information management $[1,10]$ (see also Fig. 1). In particular, establishing trust in virtual environments relies on security measures [11].

To determine and negotiate quality of service (QoS) in DITO environments Service Level Agreements (SLAs) are necessary [12]. In addition, SLAs are essential for a successful results by IT outsourcing [13]. The character of DITO implies on demand negotiation of these SLAs. In this context frameworks and mechanisms for automatic SLA management have been developed $[14,15]$. Nevertheless, the security issue has not been addressed in this context to a large extent because security measures in SLAs are not integrated yet [16]. Consequently, there is still a lack of trust in dynamic IT outsourcing services. In order to achieve higher economic efficiency by improved resource usage the integration of security measures in SLAs has, however, to be developed $[4,17]$.

The German D-Grid initiative [18] includes general infrastructure services like accounting or monitoring offered by academic service providers. Unfortunately, SLAs between these service providers and those who offer profession related services are not yet established. For instance, several biomedical Grid services require high security standards due to processing of human identifying data [19]. Such standards include the confidentiality of accounting data as well. Accounting data can support identifying patients when being revealed to a third party under particular circumstances.

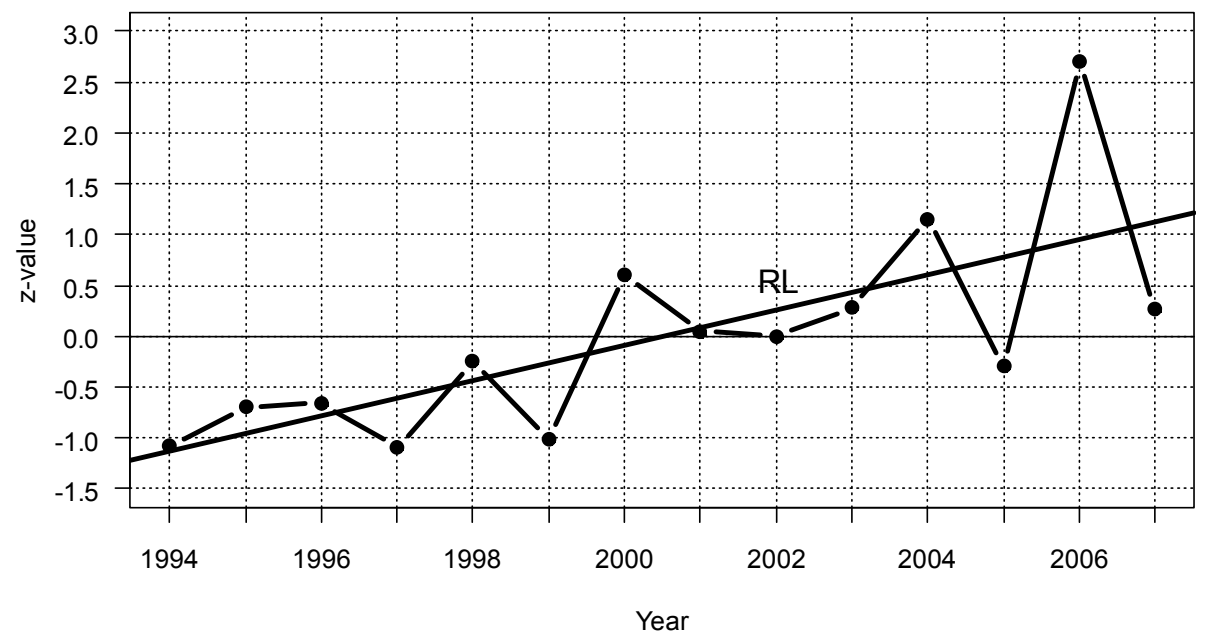

Fig. 1. Trend of the topic "trust" in information systems research: the z-value represents standardized scores (mean value $\mu=0$, standard deviation $\sigma=1$ ) of occurrences of topics in research of information management per year and RL is the linear regression line; line chart adapted from [1] 
Thus, the biomedical Grid computing project Services@MediGRID [20] is going to establish a contractual SLA with the D-Grid accounting service provider to achieve a successful technology transfer. Technology transfer means transfer of a scientific result to the "real world" [21]. In essence, successful technology transfer requires trust to be established between biomedical researchers and service providers.

In the given context it is necessary to determine the perception of SLAs by service customers and whether SLAs enable trust in DITO relationships. In addition, the opinion on the topic of security in SLAs is required to be considered. From the introduction the following hypotheses are being derived:

Hypothesis H1: Security measures in Service Level Agreements positively influence trust supported by Service Level Agreements in dynamic IT outsourcing.

Hypothesis H2: Security measures are not yet considered appropriately in Service Level Agreements for dynamic IT outsourcing relationships.

\section{Materials and Methods}

In order to get an overview at the opinion of service customers with regard to security measures in SLAs and trust a quantitative survey has been conducted. The primary objective is to verify the hypotheses $\mathrm{H} 1$ and $\mathrm{H} 2$ as well as adjacent concerns. Therefore, present and potential customers of Cloud or Grid computing services are being queried.

\subsection{Choice of Survey Location and Survey Process}

As survey location the CeBIT (http://www.cebit.de) 2010 was chosen, due to its attraction to IT experts from all over the world. The survey has been conducted on March, $4^{\text {th }}$ 2010. Additionally, Cloud computing was one of the major topics of the CeBIT exhibition in 2010. This increases the probability of encountering entities of the target group: Cloud computing customers as well as potential Cloud computing customers.

To increase the probability to encounter relevant entities the survey location was restricted to areas near exhibition booths of Cloud computing providers. In these areas randomly picked people have been interviewed. For improved results leisure visitors were excluded. The survey was conducted by two persons whose location was changed in the exhibition area.

\subsection{Questionnaire Design}

For design of the questionnaire and evaluation of the answers the software GrafStat was applied. GrafStat supports designing questionnaires, collecting answers as well as statistical analysis of the results (http://www.grafstat.de). Further analysis and graphical output of contingency tables was produced with the statistics tool $\mathrm{R}$ (http://www.r-project.org). 
Achieving results in a direct survey requires a questionnaire which can be completed by the respondents within 2 to 3 minutes. Therefore, a maximum of 12 questions was set. For a quantitative survey multiple-choice answers were used for practical reason. Since Grid and Cloud computing are more commonly known, these terms were chosen as representatives for dynamic IT outsourcing.

Question Q1: Do you already use Cloud or Grid Computing services? (e.g. Softwareas-a-Service, Platform-as-a-Service or Infrastructure-as-a-Service)

The structure of the questions begins with a general perspective by asking whether the respondent already uses Cloud or Grid computing services or not. This is intended to examine the familiarity with the respective central topic. The survey has an unspecified character with regard to particular occurrences of dynamic IT outsourcing. Thus, all three layers of IT outsourcing are encompassed: 1. Software-asa-Service (SaaS), 2. Platform-as-a-Service (PaaS), and 3. Infrastructure-as-a-Service (IaaS) [22].

Question Q2: How much do you trust Cloud or Grid Computing services by external providers?

Trust as a contemporary issue in dynamic IT outsourcing is queried by a range of high, neutral, and low level of trust in external providers.

Question Q3: Would you agree that Service Level Agreements support trust in Cloud or Grid Computing providers?

The question regarding trust in Q2 is followed by the narrowing question whether SLAs support trust in the service of dynamic IT outsourcing providers.

Question Q4: From your point of view, are Service Level Agreements supporting transparent specifications of costs and services?

In any case the transparent definition of costs and service parameters is a major concern when defining an SLA. Therefore, this topic is required to be considered.

Question Q5: Are technical and legal contents of SLA documents you have read clearly described and easy to understand?

Because the language of SLAs consists of both technical and legal expressions and wording it is necessary to include the apprehension of the respondents. The understanding of the contents depends on the qualification / background as well as clarity. Here both scopes need to be queried separately whether they are clear to the respondent or not.

Question Q6: Are transparent evaluation and report methods applied by service providers?

For DITO customers it is important to determine the QoS. In this context the service provider is required to offer a transparent evaluation solution. For decision makers the data produced by the evaluation solution is usually prepared as a report. In order to be able to make profound decisions the quality of the evaluation data is crucial. Consequently, the quality of the QoS evaluation process and its transparency to the customer is a relevant aspect. 
Question Q7: Related to your experience, are Service Level Agreements designed flexibly in order to be adjusted to technical innovations or changes in processes?

Technological advancement requires adjustment of respective business processes. Accordingly, it is compulsory to design SLAs to be easily adapted to future changes. If an SLA is designed to be adaptive, it will not be necessary to sign a whole new version of the document. Changes will be applied to the existing document by mutual agreement. This reduces administrative efforts.

Question Q8: Do you have experience in machine-negotiated Service Level Agreements in dynamic infrastructures like Cloud or Grid Computing?

As mentioned in the introduction, SLAs in dynamic IT outsourcing environments are proposed to be managed by the IT infrastructure itself. Because this is a rather new way of dealing with SLAs, the familiarity with automated SLAs is a relevant question to ask.

Question Q9: Are machine-negotiated Service Level Agreements able to establish the same level of trust as paper-based contracts?

For instance, German and U.S. law do not stipulate that a contract needs to be in writing. Contracting relationships, being signed by using IT devices e.g. via click on a URL, are accepted. Nonetheless, trust and written contracts might closely go together. Therefore, it is necessary to evaluate whether automated SLAs can fulfill the same degree of trust.

Question Q10: How would you measure the relevance of the topic "Security" in Service Level Agreements regarding Cloud or Grid Computing services?

As mentioned in the introduction, trust can be established by offering adequate security in relation to the according product or service. Security in DITO can be ensured e.g. by specification of data handling procedures or certification of the provider by a neutral institution. Based on the security measures the customer has the ability to assess the Security of Service (SoS). However, SLAs are able to include security measures and to ensure their application. To validate hypothesis H1, a range of high, neutral, and low level of relevance is queried. Because security is a concern regardless of the location of the supplier [23], differences between international and national IT outsourcing is not necessary here.

Question Q11: From your point of view, is the topic "Security" in Service Level Agreement handled with an adequate amount of importance? (e.g. the definition of preventive measures based on the workflows or risk management processes)

Addressing the introduced lack of consideration of security in SLAs it is vital to validate hypothesis H2. Security parameters can be addressed via definition of requirements, respective workflows and risk management procedures.

Question Q12: What do you expect from the use of Cloud or Grid Computing and what advantages do you see for your company?

After all, it is relevant what opportunities in dynamic IT outsourcing the respondents see for themselves or their company. Since the answers cannot be predicted or should be restricted, the type of answer is defined as free text. 
The defined scales in Q2 and Q10 are represented by values: $3=$ high, $2=$ neutral, $1=$ low based on the Likert-scale question style [24]. With the definition of numeric values average and median can be determined. Q5 aims at two different subtopics, the legal and the technical perspective and is therefore implemented as a ordinalpolytomous question type [25]. For Q1, Q3 and Q4, Q6 to Q9 as well as Q11 the dichotomous question type was applied [26].

\subsection{Evaluation Methodology}

The methodology is based on descriptive statistics in order to analyze the quantitative data. Descriptive statistics encompass the investigated frequencies of occurrence and mean values [27].

In addition, the quantitative data is categorized due to the design of the questionnaire which subdivides the respondents into two major groups. These groups are defined by Q1 as experienced and not experienced DITO customers. Based on contingency tables coherences within the data were analyzed [28]. Moreover, mosaic diagrams are used for optimal representation of the contingency table results [29].

\section{Results}

The results are described in two parts. The first part outlines the general results from the questions. In the second part relevant cross reference results are presented.

\subsection{General Survey Responses}

Within the survey 75 questionnaires were filled out in total. A majority of $57.3 \%$ of the participants already uses Cloud or Grid computing services (see Q1 in Table 1). Furthermore, $36.0 \%$ of the respondents show high confidence in external DITO providers. Further $46.7 \%$ express a neutral and $16.0 \%$ a low degree of trust (see Q2 in Table 2). On the scale from 1 (low) to 3 (high) the average degree of trust equals 2.20 according to the 74 received answers. This indicates that a majority of the participants trust IT outsourcing partners.

A positive coherence between SLAs and trust in IT outsourcing relationships is confirmed by a major share of $73.3 \%$ of the participants (see Q3 in Table 1). This supports the initial assumption. Moreover, $50.7 \%$ positive results indicate that SLAs are implemented with transparent cost and service definitions (see Q4 in Table 1). Still yet, $38.7 \%$ of the replies show the opposite. Consequently, transparency is still an issue but not a major one.

With regard to the clarity of SLA contents $29.3 \%$ of the respondents are positive about the legal details while $46.7 \%$ do not share the same opinion (see Q5 in Table 3). According to technical details, $54.7 \%$ are positive about the technical contents while $22.7 \%$ are not. The results evidently show a lack of legal clarity to the customers in SLA documents. Unfortunately, Q5 was not answered 12 times and 11 times partially responded. From the 11 partial answers, 6 legal and 5 technical answers have been skipped. 
Transparent evaluation measures and reports are offered by service providers in the opinion of $44.0 \%$ of the interviewed CeBIT visitors whereas $42.7 \%$ object (see Q6 in Table 1). This further backs up the determined lack of transparency indicated by Q4. An adaptive design of SLAs is confirmed by $45.3 \%$ of the respondents while $44.0 \%$ do not share the same opinion (see Q7 in Table 1).

Experience in machine-negotiated SLAs state $30.7 \%$ of the participants whereas a majority of $66.7 \%$ does not (see Q8 in Table 1). Subsequently, $40.0 \%$ of the interviewed CeBIT visitors trust automatically negotiated SLAs with the same level as written ones (see Q9 in Table 1). Besides, $50.7 \%$ of the interviewed visitors do not share that trust. These results generally indicate that automatic SLAs are not perceived as to be a respected instrument. The central question concerning the topic of security in SLAs was skipped by 3 respondents (see Q10 in Table 2). $72.0 \%$ of the answers show a high, $20.0 \%$ neutral, and $4.0 \%$ low relevance for security measures to be covered by SLAs. This supports hypothesis H1. According to hypothesis H2, $26.7 \%$ of the responses agree whereas $58.7 \%$ disagree whether the topic of security is being addressed appropriately in SLAs (see Q11 in Table 1).

Table 1. The results overview for the dichotomous questions

\begin{tabular}{|c|c|c|c|c|c|c|}
\hline \multicolumn{2}{|c|}{ Question } & \multirow{2}{*}{$\begin{array}{l}\text { Yes } \\
43(57.3 \%)\end{array}$} & \multicolumn{2}{|l|}{ No } & \multicolumn{2}{|c|}{ Skipped } \\
\hline Q1: & $\begin{array}{l}\text { Do you already use Cloud or Grid Computing } \\
\text { services? }\end{array}$ & & $\begin{array}{l}32 \\
\%)\end{array}$ & $(42.7$ & $\begin{array}{c}0 \\
\%)\end{array}$ & $(0.0$ \\
\hline Q3: & $\begin{array}{l}\text { Would you agree that Service Level } \\
\text { Agreements support trust in Cloud or Grid } \\
\text { Computing providers? }\end{array}$ & $55(73.3 \%)$ & $\begin{array}{l}17 \\
\%)\end{array}$ & $(22.7$ & $\begin{array}{c}3 \\
\%)\end{array}$ & $(4.0$ \\
\hline Q4: & $\begin{array}{l}\text { From your point of view, are Service Level } \\
\text { Agreements supporting transparent } \\
\text { specifications of costs and services? }\end{array}$ & $38(50.7 \%)$ & $\begin{array}{l}29 \\
\%)\end{array}$ & $(38.7$ & $\begin{array}{c}8 \\
\%)\end{array}$ & $(10.6$ \\
\hline Q6: & $\begin{array}{l}\text { Are transparent evaluation and report methods } \\
\text { applied by service providers? }\end{array}$ & $33(44.0 \%)$ & $\begin{array}{l}32 \\
\%)\end{array}$ & $(42.7$ & $\begin{array}{l}10 \\
\%)\end{array}$ & (13.3 \\
\hline Q7: & $\begin{array}{l}\text { Related to your experience, are Service Level } \\
\text { Agreements designed flexibly in order to be } \\
\text { adjusted to technical innovations or changes in } \\
\text { processes? }\end{array}$ & $34(45.3 \%)$ & $\begin{array}{l}33 \\
\%)\end{array}$ & $(44.0$ & $\begin{array}{c}8 \\
\%)\end{array}$ & $(10.7$ \\
\hline Q8: & $\begin{array}{l}\text { Do you have experience in machine- } \\
\text { negotiated Service Level Agreements in } \\
\text { dynamic infrastructures like Cloud or Grid } \\
\text { Computing? }\end{array}$ & $23(30.7 \%)$ & $\begin{array}{l}50 \\
\%)\end{array}$ & $(66.7$ & $\begin{array}{c}2 \\
\%)\end{array}$ & ( 2.6 \\
\hline Q9: & $\begin{array}{l}\text { Are machine-negotiated Service Level } \\
\text { Agreements able to establish the same level of } \\
\text { trust as paper-based contracts? }\end{array}$ & $30(40.0 \%)$ & $\begin{array}{l}38 \\
\%)\end{array}$ & $(50.7$ & $\begin{array}{c}7 \\
\%)\end{array}$ & ( 9.3 \\
\hline Q11: & $\begin{array}{l}\text { From your point of view, is the topic } \\
\text { "Security" in Service Level Agreement } \\
\text { handled with an adequate amount of } \\
\text { importance? }\end{array}$ & $20(26.7 \%)$ & $\begin{array}{l}44 \\
\%)\end{array}$ & $(58.7$ & $\begin{array}{l}11 \\
\%)\end{array}$ & (14.6 \\
\hline
\end{tabular}


Table 2. The results overview for the Likert-scale questions

\begin{tabular}{lllll}
\hline Question & Answer High & Neutral & Low & Skipped \\
\hline Q2: & $\begin{array}{l}\text { How much do you trust Cloud or 27 (36.0\%) } \\
\text { Grid Computing services by } \\
\text { external providers? }\end{array}$ & & & \\
Q10: & How would you measure the $54(72.0 \%)$ & $15(20.0 \%)$ & $3(4.0 \%)$ & $3(4.0 \%)$ \\
& $\begin{array}{l}\text { relevance of the topic "Security" in } \\
\text { Service Level Agreements } \\
\text { regarding Cloud or Grid Computing } \\
\text { services? }\end{array}$
\end{tabular}

Table 3. The results overview for the ordinal-polytomous question

\begin{tabular}{lrlll}
\hline Question & Answer Clear & Unclear & Skipped \\
\hline Q5: & $\begin{array}{l}\text { Are technical and legal contents of SLA } \\
\text { documents you have read clearly } \\
\text { described and easy to understand? }\end{array}$ \\
Legally & $22(29.3 \%)$ & $35(46.7 \%)$ & $18(24.0 \%)$ \\
& Technically & $41(54.7 \%)$ & $17(22.7 \%)$ & $17(22.6 \%)$ \\
\hline
\end{tabular}

According to expectations from Grid or Cloud computing by the participants in Q12, the question was answered 36 times. Because of free text, only the most frequently given answers are documented. With 7 times "lower costs" was the most frequent answer followed by 6 times for "higher security / availability". Additional 4 respondents expect "more flexibility / scalability". Table 1, 2, and 3 summarize the overall results. All percentages are rounded up to one place behind the decimal point.

\subsection{Contingency Table Results}

For further evaluation it is presumed that participants with DITO experience (see Q1 in Table 1) are supposed give more reliable answers. In addition, skipped answers are no further included.

Considering trust, $48.8 \%$ of the DITO users have high, $34.9 \%$ neutral, and $16.3 \%$ low confidence in external service providers (coherence: Q1, Q2; see Table 4). The mean value equals 2.20 and shows no difference in comparison to the whole population. Besides, from 42 experienced users $78.6 \%$ of the respondents agree that SLAs support trust in DITO relationships (coherence: Q1, Q3). Here, no significant difference exists compared to inexperienced users. A positive coherence exists between Q2 and Q3. A majority of the experienced users have high or neutral confidence in external providers as well as support that SLAs support such trust in external providers (see Fig. 2).

Additionally, $23(57.5 \%)$ from 40 skillful participants agree that SLAs provide a transparent specification of costs and services (coherence: Q1, Q4). Anyhow, the understanding of SLAs by experienced users is more technically oriented (coherence of Q1 and Q5). Furthermore, from 41 experienced users $23(56.1 \%)$ respond that 
transparent evaluation and report methods are applied by service providers (coherence: Q1, Q6). Considering the given 40 responses to adaptability of SLAs, 25 (62.5\%) experienced users agree (coherence: Q1, Q7).

Moreover, from 42 experienced DITO users 27 (64.3\%) are not familiar with machine-negotiated SLAs. In contrast to the general results 11 (73.3\%) of 15 who have experience with machine-negotiated SLAs and DITO state that these SLAs offer the same level of trust as their written counterparts (coherence: Q1, Q8, Q9; see Fig. 3). Therefore, machine-negotiated SLAs are mostly perceived as adequate if applied.

With regard to the importance of security in SLAs $36(85.7 \%)$ responses show high, 5 (11.9\%) neutral, and 1 (2.4 \%) low relevance (coherence: Q1, Q10). Thus, hypothesis $\mathrm{H} 1$ is assumed to be valid.

For validation of hypothesis $\mathrm{H} 2$ the importance for security in SLAs and its adequate amount of consideration are relevant (coherence: Q10, Q11). Here, 64 answers are given to both questions in total. A majority of 38 (59.4\%) respondents do not agree that security is considered in SLAs appropriately while at the same time they see high relevance for security in SLAs. In particular, a more significant majority of $27(69.2 \%)$ of the 39 experienced respondents support that statement (coherence: Q1, Q10, Q11; see Table 5 and Fig. 4). Thus, hypothesis H2 is assumed to be valid.

Table 4. Coherence between user experience and confidence in external service providers

\begin{tabular}{|c|c|c|c|}
\hline & & \multicolumn{2}{|c|}{$\begin{array}{l}\text { Q1: Do you already use Cloud or } \\
\text { Grid Computing services? }\end{array}$} \\
\hline & & Yes & No \\
\hline \multirow{3}{*}{$\begin{array}{l}\text { Q2: How much do you trust Cloud or } \\
\text { Grid Computing services by external } \\
\text { providers? }\end{array}$} & High & $21(48.8 \%)$ & $5(16.1 \%)$ \\
\hline & Neutral & $15(34.9 \%)$ & $20(65.5 \%)$ \\
\hline & Low & $7(16.3 \%)$ & $6(19.4 \%)$ \\
\hline Total & & $43(100.0 \%)$ & $31(100.0 \%)$ \\
\hline
\end{tabular}

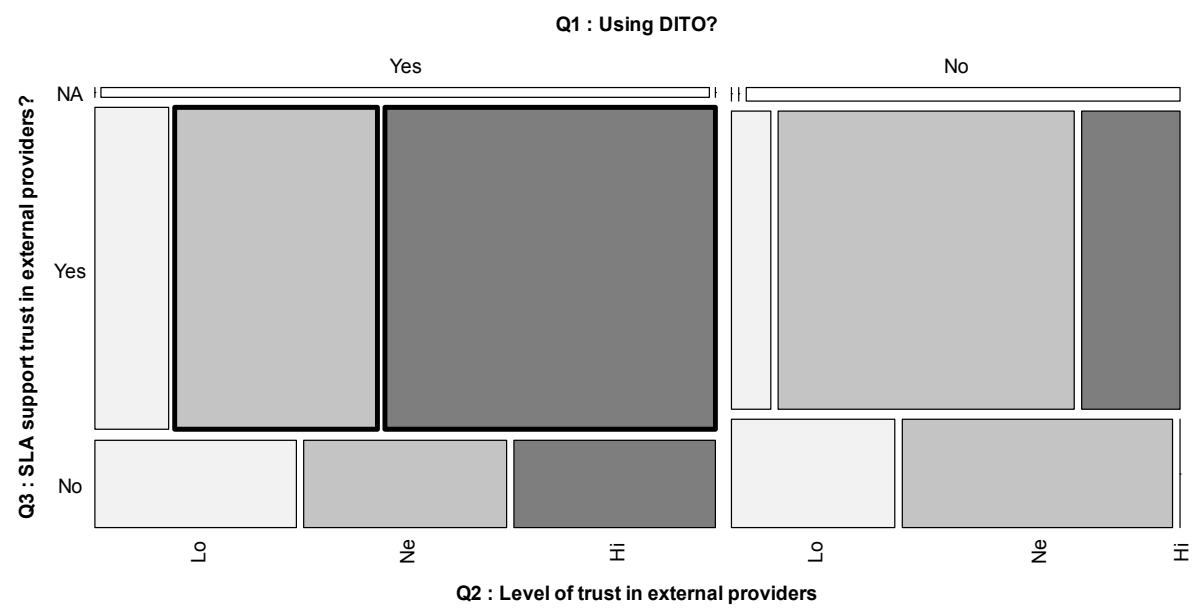

Fig. 2. Coherence between user experience, SLAs supporting trust and the level of trust in external providers 




Fig. 3. Coherence between user experience, experience and trust in machine-negotiated SLAs

Table 5. Coherence between user experience, security consideration and relevance to SLAs

\begin{tabular}{|c|c|c|c|c|c|}
\hline & & & & \multicolumn{2}{|c|}{$\begin{array}{l}\text { Q1: Do you already use Cloud } \\
\text { or Grid Computing services? }\end{array}$} \\
\hline & & & & Yes & No \\
\hline \multirow{6}{*}{$\begin{array}{l}\text { Q11: Is security } \\
\text { handled with the } \\
\text { adequate amount } \\
\text { in SLAs? }\end{array}$} & & Q10: Relevance & High & $27(69.2 \%)$ & $11(44.0 \%)$ \\
\hline & no & of security in & Neutral & $1(2.6 \%)$ & $3(12.0 \%)$ \\
\hline & & SLAs & Low & $0(0.0 \%)$ & $2(8.0 \%)$ \\
\hline & & Q10: Relevance & High & $7(17.9 \%)$ & $4(16.0 \%)$ \\
\hline & yes & of security in & Neutral & $3(7.7 \%)$ & $5(20.0 \%)$ \\
\hline & & SLAs & Low & $1(2.6 \%)$ & $0(0.0 \%)$ \\
\hline Total & & & & $39(100.0 \%)$ & $25(100.0 \%)$ \\
\hline
\end{tabular}

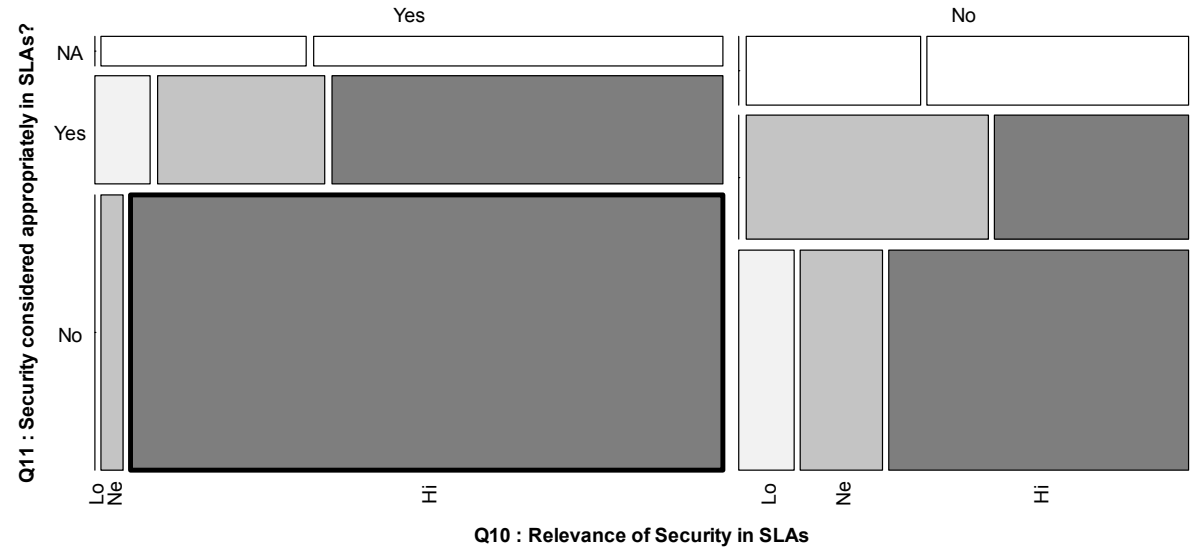

Fig. 4. Coherence between user experience, security consideration and security relevance in SLAs 


\section{Discussion and Outlook}

The relatively small number of participants in this survey does not necessarily offer a fully representative conclusion. Nevertheless, the clear results - which are also profoundly supported by the experienced share of the participants - can be assumed to be a good reference to reality.

Because a clear majority of the randomly interviewed survey participants already uses Grid or Cloud computing services indicates that distributed IT outsourcing is an important matter. Nonetheless, there is still potential to acquire new DITO customers. More clearly, as one of the respondents stated: "It is the natural path (Isaac Asimov)".

The overall high trust in DITO providers opposes present discussions on data security in social network services [30]. On the other hand, it sustains that users have strong trust in certain social network services [31]. Another example for concerns about data stored by external institutions is related to scientific data archives for long term preservation and / or open access. Researchers mostly do not like the idea to store content in data sharing environments because someone else could achieve something more significant with their data [32]. Such concerns affect possible developments on Grid and Cloud computing in the academic area and consequently the technology transfer process of Grid computing. Building up trust via security in SLAs will therefore unquestionably support prevalence of use of DITO services.

The aim of the German D-Grid initiative and of the project Services@MediGRID is a technology transfer from research and development to a commercially oriented level. Commercial - a service being paid for - also includes, in this case, the utilization of the D-Grid infrastructure as a product in the academic area. In the academic area DITO will be provided by academic IT service providers. However, as explained, SLAs are necessary as a substantial basis for the service provision. Hence, the further discussion will emphasize the requirements for SLAs by taking technology transfer into account.

\subsection{Requirements for Service Level Agreements}

Generally, hypotheses $\mathrm{H} 1$ and $\mathrm{H} 2$ are assumed to be validated by the conducted survey. Thus, security measures in SLA are important to establish trust between customers and providers of dynamic IT outsourcing. Nonetheless, those security measures are not yet embedded in SLAs. Figure 4 precisely refers to this matter. Similar experiences within the project Services@MediGRID show that the technology transfer lacks because SLAs in general and security measures covered by SLAs are still missing. For that reason the process of technology transfer, at least partly, depends on profound contractual conditions. In case of the biomedical area this necessarily encompasses security measures to be defined.

Though a majority of experienced users trusts automatic SLAs overall, written contractual agreements are still preferred over machine-negotiated alternatives. This opinion is likewise supported by the inexperienced participants. It would be important to know the particular reasons for that matter, but that was not an objective of the survey. However, a significant number of respondents have a rather technical perspective according to Q5 (see Table 3). Because of the technical focus the 
qualification of the respondents does not sustain their judgment that automatic SLAs offer the same level of trust as their written counterparts. Notwithstanding, Grid science projects like D-Grid rely on the development of automatic SLAs. In essence, it can be deducted that the lack of consideration of written contracts in scientific Grid and Cloud computing projects interferes with successful technology transfer. Above all, it can be stated that automatic negotiated SLAs require to be covered by additional written general SLAs. Even though automatically negotiated SLAs are necessary for efficiently providing ad hoc IT services, a holistic approach is considered to include a general agreement as well. This backs up the initiative of Services@MediGRID to establish the use of contractual agreements.

Further, more general, requirements for SLAs can be derived from the overall results of section 3.1. This encompasses the common necessity of transparency which includes clear specification of costs and products - respectively of the DITO services. According to the results this aspect is already adequately addressed. Yet, transparent evaluation methods like reports still offer some potential for optimization. In the same way follows the adaptability of SLAs.

\subsection{Outlook}

Since Grid and Cloud computing as specific characteristics of DITO environments are relatively new, the technology transfer process has not been entirely completed in areas like biomedicine yet. With focus on building up trust by including security measures in SLAs it can be stated that present SLAs do not support that matter to a sufficient degree at present. This is an important indication because SLAs are necessary to build up trust in dynamic IT outsourcing. Besides, definition of the security measures is required as well.

It can also be concluded that customers of IT services still rely on good old paper rather than on electronic agreements. This is required to be considered when it comes to implementing Grid or Cloud computing services successfully. Economic optimization, in the first place, does not include optimization of trust. Hence, the relevant steps toward trust have to be laid out in further research. First and foremost, in the area of biomedicine security in SLAs is necessary. Moreover, the technology transfer process of Grid and Cloud computing depends on obligatory promises by service providers. SLAs as an instrument for implementing reliability in outsourcing relationships are thus required for technology transfer in the IT context.

An interesting indication was given by 12 respondents. They stated that SLAs are technically as well as legally clear to them. Further questions revealed that these persons were originally coming from the field of law and gained additional knowledge in IT or are now working in a primarily IT related context.

Due to the fact that D-Grid has not yet established sustainable contractual relationships, the commercial IT association in Germany BITKOM has seized the opportunity by proposing the implementation of a German Cloud to the German federal government [33]. This might also lead to a major shift for support with IT resources in the academic field. Accordingly, future efforts of technology transfer of IT infrastructures have to be quicker in establishing general contractual conditions in order to be successful. 


\section{Acknowledgements}

This publication was supported by the joint project Services@MediGRID funded by the German Federal Ministry of Education and Research (BMBF), FKZ 01IG07015A$\mathrm{G}$ and the joint project WissGrid funded by the German Federal Ministry of Education and Research (BMBF), FKZ 01IG09005A-L.

\section{$5 \quad$ References}

1. Steininger, K., Riedl, R., Roithmayr, F., Mertens, P.: Fads and Trends in Business and Information Systems Engineering and Information Systems Research - A Comparative Literature Analysis. Business \& Information Systems Engineering 1(6), 411-428 (2009)

2. BEinGRID Consortium, Approaching the Cloud: Better Business Using Grid Solutions. Accessed: 2010.02.14, http://www.beingrid.eu/fileadmin/beingrid/ pr_folder/CaseStudy2/BEinGRID_CaseStudies_Booklet_Quotes_VF_LowWeb_012 010.pdf, (2009)

3. Matros, R., Stute, P., Zuydtwyck, N.H.v., Eymann, T., Make-or-Buy im CloudComputing - Ein entscheidungsorientiertes Modell für den Bezug von Amazon Web Services. Universität Bayreuth, Lehrstuhl für Wirtschaftsinformatik, Bayreuth, Bayreuther Arbeitspapiere zur Wirtschaftsinformatik, Accessed: 2009.11.15, http://opus.ub.uni-bayreuth.de/volltexte/2009/552/pdf/Paper_45.pdf (2009)

4. Dickmann, F., Kaspar, M., Lohnhardt, B., Knoch, T.A., Sax, U.: Perspectives of MediGRID. Stud Health Technol Inform 147, 173-182 (2009)

5. Google Scholar: Results for "dynamic IT outsourcing", http://scholar.google. $\mathrm{de} /$ scholar?q=\%22dynamic $+\mathrm{it}+$ outsourcing $\% 22 \& \mathrm{hl}=\mathrm{de} \& \mathrm{btnG}=$ Suche $\& \mathrm{lr}=$

6. Jain, A., Towards A Systemic View Of Organizational Dynamic IT Capability: An Empirical Assessment. University of Texas at Arlington, Arlington, Accessed: 2010.02.01, http://hdl.handle.net/10106/238 (2007)

7. Vassiliadis, B., Stefani, A., Tsaknakis, J., Tsakalidis, A.: From application service provision to service-oriented computing: A study of the IT outsourcing evolution. Telematics and Informatics 23(4), 271-293 (2006)

8. Malik, Z., Bouguettaya, A.: Trust Management for Service-Oriented Environments. Springer, New York ; Dordrecht ; Heidelberg ; London (2009)

9. Talbot, D.: Security in the Ether. Technology Review 50(1), 36-42 (2010)

10. Arenas, A., Wilson, M., Matthews, B.: On trust management in grids. In: 1st international conference on Autonomic computing and communication systems, Autonomics 2007 (Davide, F., ed.), pp. 1-7. ACM, Rome, Italy (2007)

11. Yau, P.-W., Tomlinson, A.: Using Trusted Computing in Commercial Grids. In: International Workshops on Conceptual Structures, ICCS 2007 (Akhgar, B., ed.), pp. 31-36. Springer, Sheffield, UK (2007)

12. Buyya, R., Yeo, C.S., Venugopal, S.: Market-Oriented Cloud Computing: Vision, Hype, and Reality for Delivering IT Services as Computing Utilities. The Computing Research Repository (CoRR) abs/0808.3558 (2008)

13. Goo, J., Nam, K.: Contract as a Source of Trust--Commitment in Successful IT Outsourcing Relationship: An Empirical Study. In: 40th Annual Hawaii International Conference on System Sciences (HICSS'07), p. 239a. IEEE Computer Society, Waikoloa, Big Island, Hawaii (2007)

14. Brandic, I., Music, D., Leitner, P., Dustdar, S.: VieSLAF Framework: Enabling Adaptive and Versatile SLA-Management In: Grid Economics and Business Models - 
6th International Workshop, GECON 2009 (Altmann, J., Buyya, R., Rana, O.F., eds.), pp. 60-73. Springer Berlin, Delft, The Netherlands (2009)

15. Padgett, J., Haji, M., Djemame, K.: SLA Management in a Service Oriented Architecture In: Computational Science and Its Applications - ICCSA 2005 (Gervasi, O., Gavrilova, M.L., Kumar, V., Laganà, A., Lee, H.P., Mun, Y., Taniar, D., Tan, C.J.K., eds.), pp. 1282-1291. Springer, Singapore (2005)

16. Parrilli, D.M.: Legal Issues in Grid and Cloud Computing. In: Grid and Cloud Computing (Stanoevska-Slabeva, K., Wozniak, T., Ristol, S., eds.), pp. 97-118. Springer, Heidelberg (2009)

17. Knoch, T.A., Baumgartner, V., de Zeeuw, L.V., Grosveld, F.G., Egger, K.: e-Human Grid Ecology - understanding and approaching the inverse tragedy of the commons in the e-Grid society. Stud Health Technol Inform 147, 269-276 (2009)

18. D-Grid Initiative, http://www.d-grid.de

19. Krefting, D., Bart, J., Beronov, K., Dzhimova, O., Falkner, J., Hartung, M., Hoheisel, A., Knoch, T.A., Lingner, T., et al.: MediGRID: Towards a user friendly secured grid infrastructure. Future Generation Computer Systems 25(3), 326-336 (2009)

20._Services@MediGRID, http://services.medigrid.de

21. Bozeman, B.: Technology transfer and public policy: a review of research and theory. Research Policy 29(4-5), 627-655 (2000)

22. Stanoevska-Slabeva, K., Wozniak, T.: Cloud Basics - An Introduction to Cloud Computing. In: Grid and Cloud Computing (Stanoevska-Slabeva, K., Wozniak, T., Ristol, S., eds.), pp. 47-62. Springer, Heidelberg (2009)

23. Burnett, R.: Outsourcing IT : the legal aspects : planning, contracting, managing and the law. Gower Publishing Ltd (2009)

24. Trochim, W.M.K., Likert Scaling. In: Research Methods Knowledge Base, Accessed: 2010.04.08, http://www.socialresearchmethods.net/kb/scallik.php, (2006)

25. Wikipedia contributors, Statistical survey. Wikipedia, The Free Encyclopedia, http://en.wikipedia.org/wiki/Statistical_survey, (2010)

26. Adèr, H.J., Mellenbergh, G.J., Hand, D.J.: Advising on research methods: a consultant's companion. Van Kessel, Huizen, the Netherlands (2008)

27. Eckle-Kohler, J., Kohler, M.: Eine Einführung in die Statistik und ihre Anwendungen. Springer, Berlin; Heidelberg (2009)

28. Mills, A.J., Durepos, G., Wiebe, E.: Encyclopedia of case study research. SAGE Publications, Thousand Oaks, Calif. (2010)

29. Friendly, M.: Mosaic Displays for Multi-Way Contingency Tables. Journal of the American Statistical Association 89(425), 190-200 (1994)

30. Lohr, S., How Privacy Vanishes Online. In: The New York Times, New York, USA, Accessed: 2010.04.08, http://www.nytimes.com/2010/03/17/technology/17privacy. html, (2010)

31. Bonneau, J., Preibusch, S.: The Privacy Jungle: On the Market for Data Protection in Social Networks. In: The Eighth Workshop on the Economics of Information Security (WEIS 2009), London, UK (2009)

32. Nelson, B.: Data sharing: Empty archives. Nature 461(7261), 160-163 (2009)

33. Briegleb, V., Deutsche IT-Branche will die Cloud mitgestalten. In: heise online. heise Verlag, Hannover, Germany, Accessed: 2010.03.12, http://www. heise.de/ix/meldung/Deutsche-IT-Branche-will-die-Cloud-mitgestalten-953839.html, (2010) 